\title{
An Emergency Blood Transfusion done to Stabilize the Patient for a Surgery
}

\author{
Jupaka Shashank $^{1 *}$, Basiri Dinesh ${ }^{2}$, G. Abhinav Kumar Reddy ${ }^{1}$ and K. Ramesh ${ }^{1}$ \\ ${ }^{1}$ Department of Veterinary Medicine, PVNR TVU Rajendranagar, Hyderabad, India \\ ${ }^{2}$ Department of Veterinary Surgery and Radiology, PVNR TVU Rajendranagar, \\ Hyderabad, India \\ *Corresponding author
}

\section{A B S T R A C T}

A native breed of dog, 6 years aged, $18 \mathrm{~kg}$ body weight, male was presented to the Veterinary Clinical Complex (VCC), College of Veterinary Science, Rajendranagar, Hyderabadfor left forelimb amputation, on the day of admitting,

\section{Keywords}

Dog, Hyderabad, Blood transfusion

Article Info

Accepted:

15 March 2020

Available Online:

10 April 2020 two days back got accident and has left forelimb fracture, before going to surgery advised Examination of complete blood picture count (CBP) and serum biochemistry. The complete blood picture reveled, the animal has severe anemia with reduced Heamoglobin, RBC, Platelets, PCV levels, and normal serum biochemistry levels so advised to immediate blood transfusion. The blood transfusion was successfully done from a healthy donor in hardworking of 4 hours. After one day of blood transfusion again examined complete blood picture count (CBP) and serum biochemistry levels.Haemoglobin, Total erythrocyte counts, Platelet counts and PCV have almost doubled, the patient was extremely active, good appetite, with normal micturition and defecation so admitted for surgery and successfully done left forelimb amputation, advised medications for 10 days continuously and antiseptic dressing on alternate days.

\section{Introduction}

Blood transfusion has been used as an emergency and life-saving step, since many years in human as well as animals medicine (Davidow, 2013). It is a most common practice to save the critically ill patient having low blood parameters. It is a process of transfer of homogenous blood from one individual to another of same species. Blood is a complex fluid medium of plasma having suspension of living cells, and is a very essence of life (Molison, 1976).

Transfusion medicine has gradually become more feasible in small animal practice, with improved access to blood products through collection and transfusion from on-site 
donors, and the recent advancement of storage facility for whole blood and blood constituents. Separation of specific blood constituents from whole blood helped to increase the storage period and led to the use specific blood constituents for transfusion depending on the requisite. The requirement for transfusion of blood and its components arise to sustain life of anaemic animals by improving the reduced red cell mass, and other cellular and noncellular components i.e., platelets, leucocytes, circulating hemoglobin level and blood volume that ameliorate most clinical signs.

Although it is a common procedure in clinical therapy, but not without substantial risk associated with live cells transfusion. In the US Blood Shield laws, Zuck (1990) has described blood transfusion as "unavoidably, unsafe, and inherently dangerous" procedure. These fatal risks were found to be more common in cats compared to dogs. The blood transfusion depends on several factors like type of anemia, blood group, blood parameters, animal size and blood products to be administered (Lanevschi et al., 2001). So, while transfusion physician should have thorough knowledge about transfusion medicine as well as its complication and emergency management.

Today what we are following as blood transfusion technique from one animal to another of same species is not a single day achievement but it took long journey and contribution of the various researchers. History begins with the revolutionized discovery of William Harvey's theory of circulation (1628), this made possibilities of advancement in this area. In early 1600, Richard Lower carried out the first canine to canine blood transfusion and studied canine blood groups. Then one effort made by Lower and Denis transfusion between heterologous species lamb, dog and human, they given premise "like transfuses like". In 1667 the Frenchman Prosper Denis transferred the blood of a lamb into a young man but resulted in severe anemia and thus the concept of transfusion fell out of favor. Karl Lansteiner discovered blood groups in 1900, and emphasized the importance of cross matching prior to transfusion. The method of transfusion from artery to vein in dogs was performed by George Crile (1907).

First time citrate was used as anticoagulant for blood and transfused safely in to dogs (Hustin, 1914). Further, the amount of citrate to be transfused safely in dogs as an effective anticoagulant was determined by Richard Lewisohn (1915). The citrated blood can be stored for two days and transfused effectively in anemic dogs and guinea pigs (Weil, 1915). When certain additive is added in citrated blood can be stored up to 14 days and transfused with success (Rous and Turner, 1916). These steps of easier to store for a longer period made development for blood bank and to make transfusion as a routine procedure (Zimmerman and Howell, 1932). The six types of antigenic blood groups were described between years 1937 to 1949 . Rubenstein (1968) identified additional blood group.

\section{Materials and Methods}

The present investigation was carried out in the diagnostic laboratory, Department of Veterinary Clinical Complex, and Department of Veterinary Surgery and Radiology, College of Veterinary Science, Rajendranagar, Hyderabad. The owner of the animal brought for surgery of left forelimb amputation with a history of forelimb fracture by accident.Before going to surgery, for detailed examination of blood parameters,advised complete blood picture count (Table 1), and Serum biochemistry (Table 2) examination. A part from blood transfusion, prepare the slides 
with anticoagulant like Heparin (Fig. 1), observed cross matching of donor's blood with recipient's blood (Fig. 2), and observed compatibility under microscope, 40X (Fig. 3), noticed negative for agglutination reaction. Then after forwarded to blood transfusion (Fig. 4).

\section{Results and Discussion}

By the condition of animal (Conjunctival mucous membrane and buccal mucous membrane both in pale) and poor haematological values, went for blood transfusion. apart from this, selected a healthy donor (has normal haematological parameters, and normal kidney and liver functions), and went for a blood transfusion and successfully done in a hardworking of four hours (Fig. 5), and both animals conditions (donor and recipient) normal after transfusion (Fig. 6), after one day of blood transfusion again examined the recipient's complete blood picture count (Table 1), and serum biochemistry level (Table 2), by these identified Haemoglobin, Total erythrocyte count, Platelet count and PCV have almost doubled, the patient was extremely active, good appetite, with normal micturition and defecation, so admitted for surgery and successfully done left forelimb amputation (Fig. 7), apart from post-operative care, advised medications for 10 days continuously @ Inj. DNS - $100 \mathrm{ml}$ slow I/V, AC-VET (Ampicillin+Cloxacillin ) $-180 \mathrm{mg} \mathrm{I} / \mathrm{M}$, Meloxicam-3.5 mg, I/M, Inj. Toxol- $1.5 \mathrm{ml}$ I/M, Inj. Avil - 0.6ml I/M, and Supportive therapy with Syrup : Platogrow : $2 \mathrm{ml}-\mathrm{P} / \mathrm{O}$ BID, Syrup : Sharkoferrol : $2 \mathrm{ml}-\mathrm{P} / \mathrm{O}$ BID for 15 days., and antiseptic dressing on alternate days.

Generally, Adverse reaction during transfusion of blood and its products are very frequent phenomenon and occur in about one of hundred transfusions in human (Delaney,
2016). A similar type of reactions also happens frequently in small animals but they are not well documented. These reactions may occur due to improper cross matching, faulty storage or administration. The most common adverse consequences occur immediately or while transfusion are acute hemolytic reaction, anaphylactic or allergic reactions. Some of the complications are seen later such as: delayed hemolytic transfusion reaction, immunogenic or non-immunogenic reactions, hypothermia, citrate toxicity and heart failure (Lanevschi et al., 2001; Bhikane et al., 2002; Amalendu Chakrabarti, 2006). The prevention and management of adverse reaction include various steps like: selection of ideal donor, proper cross matching and blood storage, eagle monitoring of recipient during transfusion, stop immediately if any adverse reaction is seen, antihistaminic or corticosteroid usage to control allergic and anaphylactic reactions, epinephrine is the drug of choice for adverse transfusion reaction, antipyretic if fever and intravenous administration of calcium preparation in citrate toxicity.

In this case we collected few blood from donor and recipient for cross matching test, finally observed negative for agglutination i.e., Donor and Recipient blood groups are compatible and it's clear for blood transfusion, and successfully transfused into recipient's body by intravenous. Generally, the preferred route of transfusion is slow intravenous but sometimes intraperitoneal or intramedullary can also be used. The recipient animal bodyweight is $18 \mathrm{~kg}$ so totally we transfused $162 \mathrm{ml}$ of blood, Maximum rate of transfusion in normovolemic animal @ 10-20 $\mathrm{ml} / \mathrm{kg}$ body wt. per hour, hypovolemic animal @ 20-60 ml/kg body wt. per hour, in cardiac failure animal is $4 \mathrm{ml} / \mathrm{kg}$ body wt. per hour. After blood transfusion, the PCV level of $25 \%$ to $35 \%$ in $\operatorname{dog}$ and $20 \%$ to $25 \%$ in cats are desirable (Slatter, 2003). 
Table.1 Haematological parameters before and after blood transfusion

\begin{tabular}{|c|c|c|c|}
\hline \multicolumn{4}{|c|}{ Haematological analysis } \\
\hline Parameters & Normal Values & $\begin{array}{c}\text { Before blood } \\
\text { transfusion }\end{array}$ & $\begin{array}{c}\text { After blood } \\
\text { Transfusion }\end{array}$ \\
\hline Hemoglobin $(\mathbf{g} / \mathbf{d l})$ & $9-16$ & 5.0 & $\mathbf{8 . 7}$ \\
\hline PCV $(\boldsymbol{\%})$ & $38-52$ & 23.8 & $\mathbf{4 3 . 0}$ \\
\hline RBC $(\mathbf{1 0} / \boldsymbol{\mu l})$ & $5-10$ & 3.5 & $\mathbf{5 . 1}$ \\
\hline Platelets $(\boldsymbol{\mu l})$ & $200-460$ & 180 & $\mathbf{3 4 0}$ \\
\hline WBC $(\mathbf{1 0} \mathbf{3} / \boldsymbol{\mu l})$ & $4-12$ & 20.7 & $\mathbf{2 4 . 2}$ \\
\hline Neutrophils $(\mathbf{\%})$ & $51-72$ & 80 & $\mathbf{8 5}$ \\
\hline Lymphocytes(\%) & $8-35$ & 16 & $\mathbf{1 2}$ \\
\hline Monocytes $(\mathbf{\%})$ & $1-9$ & 02 & $\mathbf{0 2}$ \\
\hline Eosinophils $(\mathbf{\%})$ & $0-9$ & 05 & $\mathbf{0 3}$ \\
\hline Basophils & $\mathbf{0 - 2}$ & $\mathbf{0}$ & $\mathbf{0}$ \\
\hline
\end{tabular}

Table.2 Biochemical parameters before and after blood transfusion

\begin{tabular}{|c|c|c|c|}
\hline \multicolumn{4}{|c|}{ Biochemical analysis } \\
\hline Parameters & Normal values & $\begin{array}{c}\text { Before blood } \\
\text { transfusion }\end{array}$ & $\begin{array}{c}\text { After blood } \\
\text { transfusion }\end{array}$ \\
\hline SGPT (IU/L) & $10-88$ & 25.4 & $\mathbf{2 8 . 3}$ \\
\hline SGOT (IU/L) & $10-80$ & 27.0 & $\mathbf{3 1 . 2}$ \\
\hline Bilirubin (mg/dl) & $0.1-1.2$ & 0.1 & $\mathbf{0 . 4}$ \\
\hline Albumin (gm/dl) & $2.7-4.4$ & 2.23 & $\mathbf{2 . 4}$ \\
\hline BUN (mg/dl) & $10-25$ & 19 & $\mathbf{1 7}$ \\
\hline Creatinine (mg/dl) & $\mathbf{0 . 8 - 1 . 5}$ & $\mathbf{1 . 2}$ & $\mathbf{0 . 9}$ \\
\hline
\end{tabular}

R Heparin Injection IP $5000 \mathrm{IU} / \mathrm{ml}$

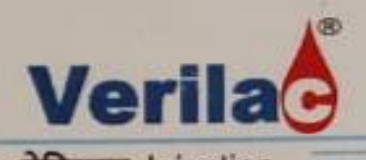

वेरिलाक Injection

For intravenous/ Subcutaneous use oniy

\section{$1 \times 5 \mathrm{ml}$}

D

R

RD

Meguillex

Fig.1 Preparation of slides with Anticoagulant (Heparin) 


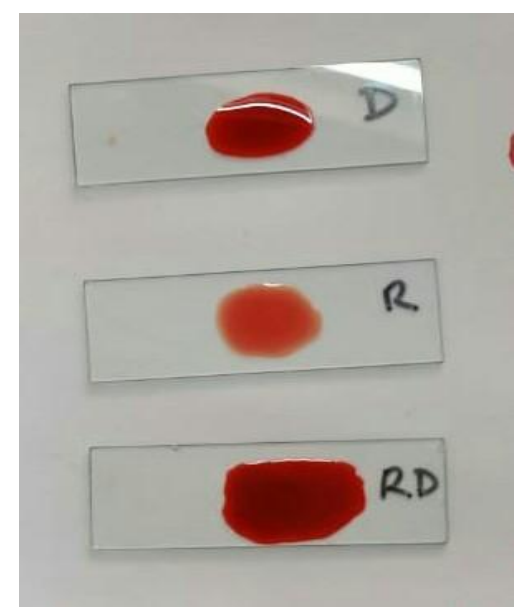

Fig.2 Cross matching test between both blood groups (D-Donor, R-Recipient)

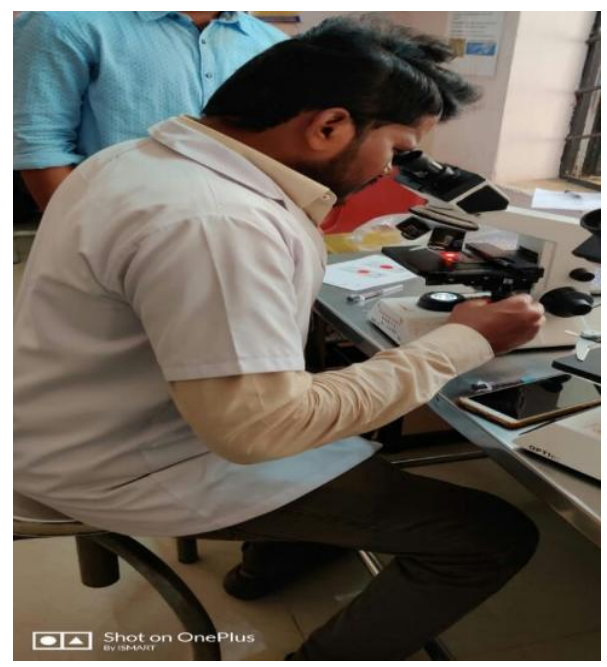

Fig.3 Identifying compatibility under microscope, $40 \mathrm{X}$

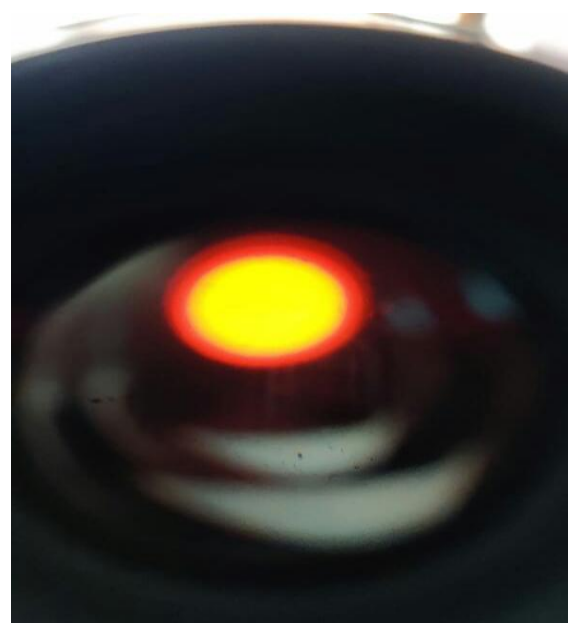

Fig.4 Negative for agglutination (Donor and Recipient blood groups are compatible)

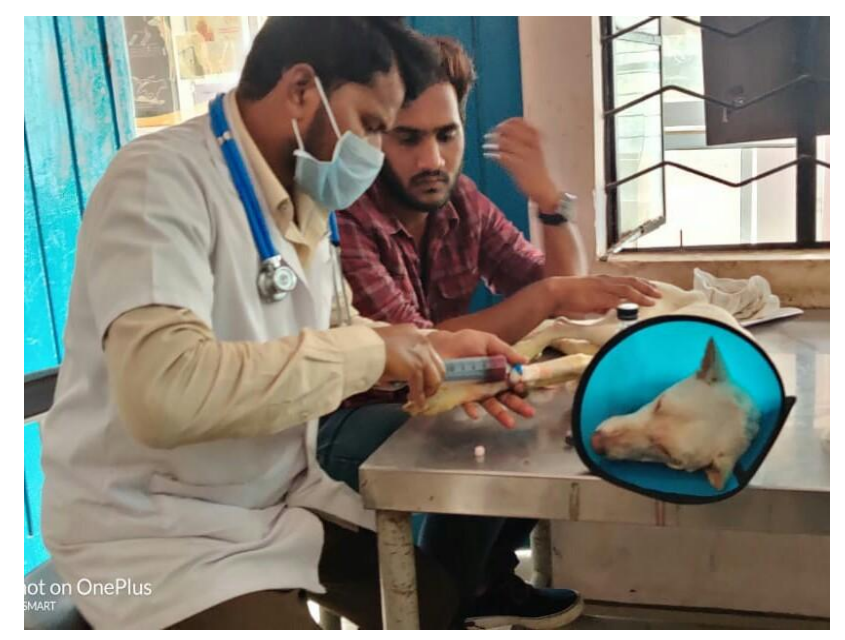

Fig. 5 Infusion of collected blood into Recipient's body 


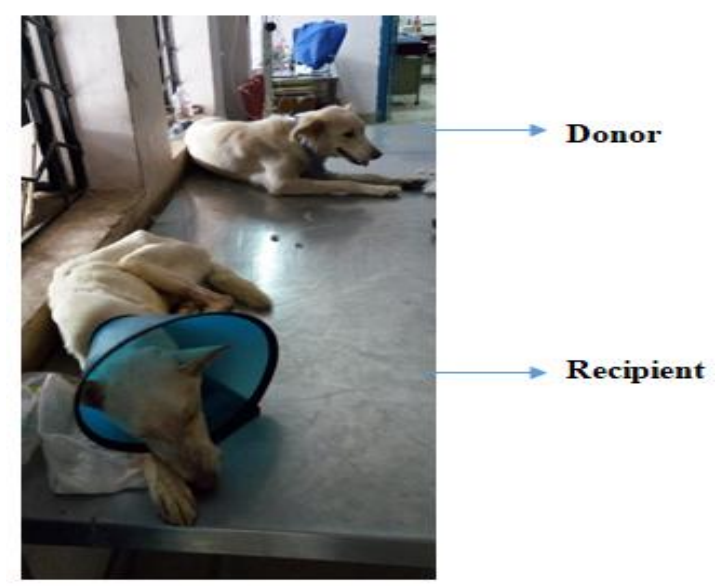

Fig. 6 After blood transfusion
The blood transfusion is a very useful and lifesaving step in critically ill patient, compromised with lower oxygenation capacity of blood due to decrease in its volume or cellular content. But still, transfusion is not without risk of adverse reaction. We can reduce these reactions by taking various mentioned precautions prior or during blood transfusion. There is a need of advancement in blood transfusion practices in small animal with safety and proper protocol.

\section{Acknowledgement}

The author wish to express sincere thanks to staff and students of College of Veterinary Science, Rajendranagar, Hyderabad. for providing the support and technical assistance in completion of this study.

\section{References}

Davidow B (2013). Transfusion medicine in small animals. Vet Clin N Am Small 43: 735-756.1.

Mollison PL (1976). Blood transfusion in clinical medicine.6thedn. ELBS. Blackwell

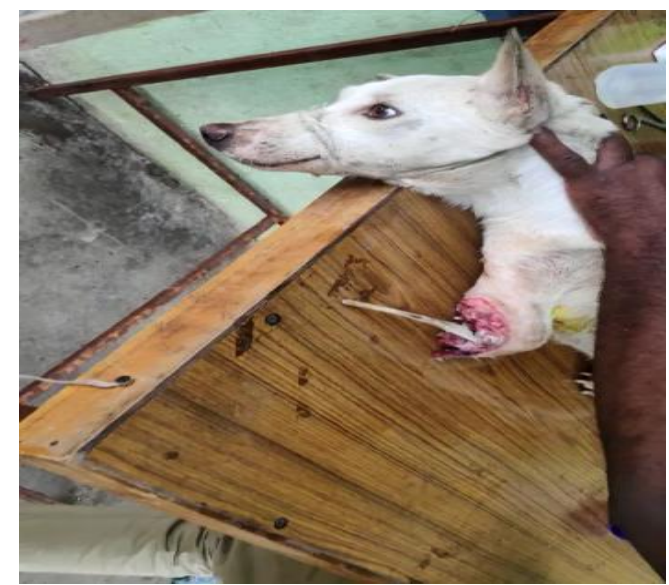

Fig. 7 Amputation of left forelimb

Scientific Publications, Oxford and Edinburgh. 332-337.

Zuck TF (1990). Legal liability for transfusion injury in the acquired immunodeficiency syndrome era. Arch Pathol Lab Med 114: 309-15

Lanevschi A and Wardrop KJ (2001). Principles of transfusion medicine in small animals. Can Vet J 42: 447.

Delaney M, Wendel S, Bercovitz RS, Cid J, Cohn C, Dunbar NM, and Van De Watering L (2016). Transfusion reactions: prevention, diagnosis, and treatment. The Lancet, 388(10061), 2825-2836.

Lanevschi A and Wardrop KJ (2001). Principles of transfusion medicine in small animals. Can Vet J 42: 447.

Bhikane AU and Kawitkar SB (2002). Blood transfusion and fluid therapy. In: Hand book of veterinary clinicians. 1stedn.Krishna pustakalaya, Latur 325-329.

Amalendu Chakrabarti (2006). Text book of clinical veterinary medicine. 3rdedn. Kalyani publishers, New Delhi 701.

Slatter DH (3nd Ed.), (2003). Textbook of small animal surgery (Vol. 1). Elsevier Health Sciences.

\section{How to cite this article:}

Jupaka Shashank, Basiri Dinesh, G. Abhinav Kumar Reddy and Ramesh, K. 2020. An Emergency Blood Transfusion done to Stabilize the Patient for a Surgery. Int.J.Curr.Microbiol.App.Sci. 9(04): 2079-2084. doi: https://doi.org/10.20546/ijcmas.2020.904.249 